\title{
Leitura em língua estrangeira: as dificuldades do leitor sob o ponto de vista da teoria da eficiência verbal
}

\author{
Leonilda Procailo*
}

\begin{abstract}
RESUMO
O presente artigo tem como tópico a capacidade de leitura de textos de divulgação científica em língua estrangeira, por parte de leitores universitários, de nível de graduação e pós-graduação. A hipótese do estudo, baseada na teoria da eficiência verbal de Perfetti $(1985,1988,2001)$ é que o vocabulário da língua alvo poderia ser um dos principais obstáculos na leitura. O estudo foi realizado com dez alunos-participantes de nível intermediário de língua inglesa em um instituto de línguas. O instrumento utilizado foi o protocolo verbal em que os participantes eram solicitados a relatar oralmente o que haviam entendido após cada parágrafo lido em silêncio. À medida que liam, deveriam sublinhar as palavras ou expressões que não conheciam ou cuja tradução não sabiam. Os resultados sugerem que grande parte da dificuldade de processamento da informação é gerada pelo desconhecimento do léxico, que, juntamente com outros fatores como o não conhecimento do tópico, da organização formal de um determinado gênero de texto e do esquema geral de pesquisa contribuem para uma leitura menos profunda. A dificuldade com o léxico pode ser visto como um elemento detonador da dificuldade em se acionar esquemas, pois demanda muito dos recursos do sistema da memória.
\end{abstract}

Palavras-chave: leitura em LE, vocabulário, memória, esquemas.

\begin{abstract}
This article focuses in the ability of under-graduate, graduate and post-graduate students to read popularized scientific articles, or press releases. The assumption, based on VET (Verbal Eficiency Theory) by Perfetti $(1985,1988,2001)$, is that the vocabulary of the target language could be one of the main constraints in reading comprehension. This study was conducted with ten participants studying the English language in the intermediate level in a language institute. Verbal protocols were used and the participants were asked to retell orally what they had understood after reading each paragraph silently. As they were reading, they should underline unfamiliar words or expressions. The results suggest that many difficulties are generated by unknown vocabulary that, along with other factors such as unfamiliarity with the topic, with the formal schema and the research schema, can contribute to a shallow level of reading. The difficulty with vocabulary can be seen as a factor that impairs the activation of schemata, as it demands a great deal from the resources of the memory system.
\end{abstract}

Keywords: reading in a foreign language, vocabulary, memory, schemata.

\footnotetext{
* Leonilda Procailo é mestre em Lingüística e atualmente leciona inglês nas Faculdades Santa Cruz de
} Curitiba. 


\section{Introdução}

Meu objetivo neste artigo é discutir os resultados de parte do trabalho realizado na minha dissertação (PROCAILO, 2007) sobre a relação leitura e conhecimento do léxico.

Este artigo está subdividido em quatro partes: na primeira, apresento brevemente algumas discussões sobre leitura e processamento de informação. Na segunda, apresento e defino o sistema de memória sob o ponto de vista da psicologia cognitiva. Na terceira, resumo a teoria que guiou este estudo e, finalmente, na quarta, discuto as implicações do estudo para o ensino da leitura baseando-me em parte dos dados coletados.

\section{1 - Leitura: decodificação ou interação?}

A leitura tem sido o assunto mais explorado e talvez o processo menos compreendido em educação. No que se refere à leitura em língua inglesa, apesar da grande quantidade de livros e artigos dedicados ao estudo do ensino desta habilidade, muito se questiona ainda sobre quais os obstáculos que impedem o leitor de ter uma leitura fluente. A falta de fluência e, conseqüentemente, de segurança é um dos principais motivos que levam estudantes a buscarem cursos de leitura na tentativa de melhorar o desempenho, principalmente aqueles que pretendem cursar a universidade e seguir adiante no mestrado e doutorado desenvolvendo pesquisas (CARRELL, 1988, p. 01).

Como conseguir mais eficiência na construção do significado? Como reduzir o grau de incerteza pela qual o leitor de língua estrangeira (LE) passa ao abordar um texto?

Processamentos de leitura como top-down, ou processamento descendente, e bottomup ou processamento ascendente, têm sido discutidos e aplicados no ensino da leitura nas últimas décadas. No processamento descendente o leitor ativa seu conhecimento ou um esquema acerca do conteúdo a ser lido, ajudando-o no reconhecimento do novo. No

processamento ascendente, o leitor utiliza mais profundamente seu conhecimento lingüístico e trabalha a decodificação do texto, conhecimento que está relacionado ao uso da forma para apreensão do conteúdo.

O processamento descendente assegura que as informações vindas do texto que são consistentes com as expectativas do leitor sejam facilmente assimiladas, uma vez que terão sido parcialmente processadas (ADAMS, 1980, p. 12). Enquanto isso, o processamento ascendente garante que o leitor estará atento para qualquer informação nova e que não esteja 
de acordo com suas hipóteses sobre o conteúdo do texto. A integração de ambos os processamentos tem sido a idéia defendida pelos estudiosos para uma melhor compreensão do significado do texto, pois o funcionamento do sistema depende tanto da informação na mente do leitor, quanto da impressa no texto. Para um leitor iniciante, por exemplo, o problema pode estar em que ele falha ao adotar uma das estratégias ou adota uma única ao extremo.

A teoria dos esquemas ${ }^{\dagger}$ revela muito sobre o quanto o leitor traz para a interação textoleitor (ativação descendente) ou o quanto o texto pode evocar na memória do leitor para que este consiga ativar o processamento ascendente. Ajuda também a explicar como, muitas vezes, interpretações ricas são derivadas de um texto restrito ou curto ou, o contrário, interpretações restritas são extraídas de um texto rico (RICHGELS, 1982, p. 57).

Segundo KATO, "O acionamento de um esquema pode levar ao acionamento sucessivo de seus subesquemas ou de esquemas que lhe são superordenados, fazendo o leitor predizer muito do que o texto vai dizer ou adivinhar aquilo que não está explícito" (1999, p. 52). Assim um leitor que tenha uma leitura equilibrada entre descendente e ascendente irá interpretar as informações do texto a partir de pistas nele contidas e de acordo com seu conhecimento prévio.

Porém, para um leitor menos habilidoso, a dificuldade está justamente em saber adotar a melhor estratégia na leitura. Ou ele vai se apoiar demasiadamente no vocabulário e não vai interagir com o texto, ou um leitor que já possui pouco conhecimento de vocabulário irá se apoiar muito no contexto, deixando de evoluir e o problema permanecerá, pois esse leitor não irá aumentar seu vocabulário para leituras futuras. ROTT (2005, p.96) salienta que a compreensão de uma palavra no seu contexto não necessariamente resulta numa conexão forma-significado, ou se esta conexão acontece isto pode não resultar numa entrada robusta da palavra no léxico mental, então não leva ao aprendizado. Dependendo dos objetivos do leitor, se este quiser melhorar suas habilidades para leitura de textos científicos ou técnicos, a exata apreensão de informações específicas é crucial. Apoiar-se no contexto, portanto, não garantirá uma leitura abrangente e a compreensão geral somente não basta.

\footnotetext{
$\dagger$ Na definição de RUMELHART (1980, p. 33-34): "Esquemas são empregados no processo de interpretação de dados sensoriais (tanto lingüísticos quanto não-lingüísticos), no acesso às informações da memória, na organização de ações, na determinação de objetivos, na alocação de recursos, e , geralmente, para guiar o fluxo de processamento no sistema." (Tradução da autora)
} 


\section{2 - A leitura sob um enfoque psicolingüista - o papel da memória}

Todos os processos que envolvem lembrança, compreensão de texto, julgamentos, tomada de decisões, solução de problemas estão na Psicologia Cognitiva (REISBERG, 2001,

p. 06). O psicólogo cognitivista alia a preocupação com a observação do comportamento e o seu registro à noção de que nem todas as instâncias do processo são observáveis; terão, portanto, que ser inferidas daquilo que se pode perceber conscientemente. A leitura segundo HAMPSON \& MORRIS, “[...] é uma tarefa que mostra muito sobre o funcionamento integrado do sistema cognitivo" (op. cit., p. 200, tradução da autora). Ela envolve língua, memória, percepção, atenção, compreensão e outras atividades cognitivas que funcionam juntas para extrair significado da escrita de uma maneira eficiente. De acordo com REISBERG (op. cit., p. 05), para entendermos uma estória qualquer desempenhamos atividades, geralmente sem percebermos, usando informações da memória, integrando informação já obtida com o que se lê, fazendo inferências. Porém, tudo deve ser rápido para que não se perca a compreensão do que se lê.

Para melhor compreensão de como se dá o processamento da informação no momento da leitura, faz-se necessária uma breve explicação de quais elementos da memória são envolvidos na atividade da leitura. Freqüentemente referimo-nos à memória como uma unidade em si, com localização e limites definidos, como se pudéssemos compará-la a um pente de memória do computador. Na verdade, a memória é um processo que compreende vários passos.

Como ilustração, pensemos em como uma criança ao iniciar o processo de leitura começa decodificando palavras. Nesta fase, ela não consegue de fato interpretar o que está lendo e muito provavelmente não se lembrará do que leu na primeira sentença assim que iniciar a segunda. Uma explicação poderia ser a de que o sistema cognitivo da criança nesta idade, cinco ou seis anos, não está totalmente desenvolvido.

Percebe-se que para haver compreensão do todo é necessário construir inferências através das palavras, das sentenças e dos parágrafos. A memória de curto prazo (MCP) refere-se ao tipo de memória onde a informação é processada para se obter significação. A primeira discussão séria sobre a MCP como uma entidade cognitiva separada foi a de GEORGE MILLER (1956) com o seu artigo The Magical Number Seven, Plus or Minus Two: Some Limits on Our Capacity for Processing Information. Miller argumentou que nossa capacidade de processamento de informação encontra um obstáculo que é o da quantidade de "porções". Na maioria das vezes, o ser humano é capaz de armazenar aproximadamente sete 
unidades ou porções num dado momento, independentemente do tamanho das porções. Segundo ele, a memória é sensível somente ao número de porções e não ao tamanho delas. Desta forma, o ser humano consegue processar mais informações se agrupá-las em conjuntos significativos. Um exemplo seria memorizar os números de um telefone em grupos de dois, três ou quatro números. O trabalho seria o de lembrar os grupos e não os números separadamente. Essa teoria de MILLER sobre o "engarrafamento" no sistema da memória causado pelo excesso de informação fornecerá subsídio para o estudo em questão.

De acordo com BRUNING et al (2004, p. 15), tradicionalmente, a memória é dividida em três estágios: aquisição, armazenamento e recuperação. Para que haja memorização, a informação deve ser adquirida e adicionada ao sistema. Ao ser armazenada deve ser passível de recuperação quando necessária. Na década de 50 os cientistas cognitivos criaram modelos que abrangem esses três estágios. Esses modelos refletiam a influência do computador como uma metáfora da cognição humana. Os modelos de processamento de informação e suas características comuns ficaram conhecidos como modelo modal. No modelo modal, a informação entra na MCP assim que passa pela memória sensorial. A memória sensorial, neste modelo, refere-se ao processo de percepção inicial que identifica o estímulo. Após ser processada pela sensorial a informação passa para a MCP onde recebe processo de significação. Se a informação for relevante aos propósitos do indivíduo, ela é armazenada na memória de longo prazo. Segundo HAMPSON \& MORRIS (passim), acreditava-se que a retenção da informação na MCP era fonêmica em sua natureza e poderia ser perdida ao longo de alguns segundos se não fosse evocada por um ensaio do indivíduo através da repetição para si mesmo. Então somente a informação seria transferida para um armazenamento de longo prazo, como resultado da quantidade de tempo que ficou na MCP e do número de vezes que foi repetida. Assim como a sensorial, a MCP é limitada e pesquisas investigam ainda como a informação é acessada nela. Dúvidas sobre como a informação é trabalhada nesse estágio da memória levaram os pesquisadores a se desencantarem com o modelo e Alan Baddeley (1974, e desenvolvido por Baddeley em 1986, 2001) propôs um modelo chamado memória de trabalho (MT). Baddeley e seus colegas, principalmente Graham Hitch, propuseram acrescentar outros componentes à memória e fazer distinções importantes entre os subprocessos da MCP que mantém a informação e os que a processam ativamente. Eles estavam interessados na natureza ativa dessa parte da memória e sua dinâmica interna e , portanto, preferiram usar o termo memória de trabalho.

A MT ajuda a explicar como retemos informação desde o início da leitura de um texto até o seu final. Como integramos informação conhecida com nova e articulamos inferências 
por entre os parágrafos. Pesquisas na PC revelam que a MT é um dos responsáveis por essa tarefa. A MT retém informação de uma maneira que fique acessível quando necessária. Ao lermos, se decodificarmos o sentido da primeira sentença, armazenamos seu conteúdo semântico na MT para usarmos durante toda a leitura, integrando todas as informações do texto. Às informações do texto, integramos conhecimento de mundo, e isso acontece de sentença para sentença, que é quando a MT é ativada e também ao usarmos a memória de longo prazo (MLP). STERNBERG (2000, p. 215) apresenta uma perspectiva da MT integrada a MLP e a MCP sob o ponto de vista de pesquisadores como Cantor \& Engle, 1993; Engle, 1994; Engle, Cantor \& Carullo, 1992, que colocam a MT como um sistema que recebe informação da MLP e a transfere para a MCP: "As memórias de curto prazo, de trabalho e de longo prazo podem ser imaginadas como esferas concêntricas encaixadas, nas quais a memória de trabalho contém apenas a porção ativada mais recentemente da memória de longo prazo, e a memória de curto prazo contém somente uma porção muito pequena e transitória da memória de trabalho".

Na MLP temos uma espécie de biblioteca mental. Lá armazenamos conhecimentos que adquirimos ao longo de nossa vida. Os conhecimentos são ativados e evocados pela MT quando solicitados para trabalhar a informação nova. Esses conhecimentos são divididos em três e BRUNING et al (op. cit., p. 38-39) os apresenta desta forma:

a) Conhecimento Declarativo - refere-se ao conhecimento factual, ou seja, 'o que'. Um exemplo é saber que o Iguaçu é um rio que nasce no Paraná. Tulving $(1972,2002)$ e Squire (1987) propõem como subsistemas do conhecimento declarativo a Memória Semântica que se refere a conceitos e princípios gerais e associações entre eles. $\mathrm{O}$ fato de sabermos que rosas têm espinhos ou que maçãs são verdes ou vermelhas são conceitos armazenados na memória semântica. Segundo SCHANK \& ABELSON (1977, p. 18), essa é a memória que armazena as palavras de uma forma hierárquica usando membros de uma classe como ligação básica. Por exemplo, canário está ligado a pássaro e a animal numa espécie de árvore hierárquica ou rede semântica.Os conceitos são ligados entre si por nódulos. Cada nódulo na rede representa um conceito. Estes se ligam com todos os outros conceitos na memória semântica (SAMUELS e KAMIL, 2002, p. 205). Outro subsistema é a Memória Episódica. Nela armazenamos conhecimento autobiográfico como eventos de nossa vida, nossa infância, vida escolar e assim por diante. 
b) o segundo conhecimento é chamado de Procedural ${ }^{\ddagger}$. É um conhecimento que nos faz desempenhar tarefas automaticamente. Refere-se ao 'como' proceder: fazer café, dirigir, andar de bicicleta são alguns exemplos;

c) o terceiro conhecimento é o Condicional que engloba os dois tipos de conhecimento anteriores. Ao usarmos nosso conhecimento de matemática para resolvermos problemas na vida real, estamos integrando os conhecimentos Declarativo e Procedural. (BRUNING et al, loc. cit., p. 37 - 39).

Como todos esses tipos de conhecimento se relacionam com o ato de ler? Para BRUNING et al (loc. cit., p. 244, tradução da autora):

Obviamente, ambos os processos, a memória de trabalho e a memória de longo prazo são necessários para tornar a leitura significativa. A construção do significado depende da interação das duas. A informação nova precisa ser mantida vívida na memória de trabalho enquanto a informação mais velha é trazida da memória de longo prazo. Com esta interação em mente, alguns pesquisadores que têm examinado a leitura sob uma perspectiva da memória (e.g., Breznitz \& Share, 1992); argumentam que a decodificação mais lenta que o normal pode significar uma exigência maior que o normal da memória de trabalho e interferir na leitura significativa. Quando as palavras são decodificadas vagarosamente, cada significado tem que ser mantido na memória por mais tempo para que o leitor entenda o significado da sentença ou parágrafo.

Porém, a transferência de informação da MT para a MLP não é assim tão simples. No modelo de Baddeley, dentro da MT existem pelo menos outros três sub- sistemas que fazem com que a informação permaneça lá por alguns instantes e passe por um processo de significação. No centro deste processo está o Supervisor Central (SC) e seus dois assistentes, o registro visuo-espacial e o circuito articulatório fonológico ${ }^{\S}$, o SC controla os outros componentes e é responsável pela compreensão, planejamento e controle das atividades cognitivas do indivíduo, assim como num modelo chefe-subordinado (HAMPSON \& MORRIS (op. cit., p. 34.) Os dois assistentes do SC servem como meros recipientes de informação. A função deles não é muito sofisticada e são úteis somente para armazenar informação por alguns segundos e nada mais. Caso seja necessário trabalhá-la, interpretá-la ou analisá-la, os assistentes não o fazem. O SC é que desempenha tal tarefa. No entanto, seu papel é muito importante. No modelo de Baddeley apresentado por BRUNING et al (op. cit., p. 28-29) (figura 1), o assistente registro visuo-espacial permite segurar a informação visual

O termo Procedural foi assim traduzido do inglês por Maria Regina Borges Osório em STERNBERG, R.J. Psicologia Cognitiva. Porto Alegre: Artmed, 2000, p. 217.

$\S$ id. 
na MCP ou MT e processá-la e o circuito articulatório fonológico nos permite segurar a informação acústica, verbal temporariamente, via ensaio, por dois a quatro segundos.

Figura $1^{*}$

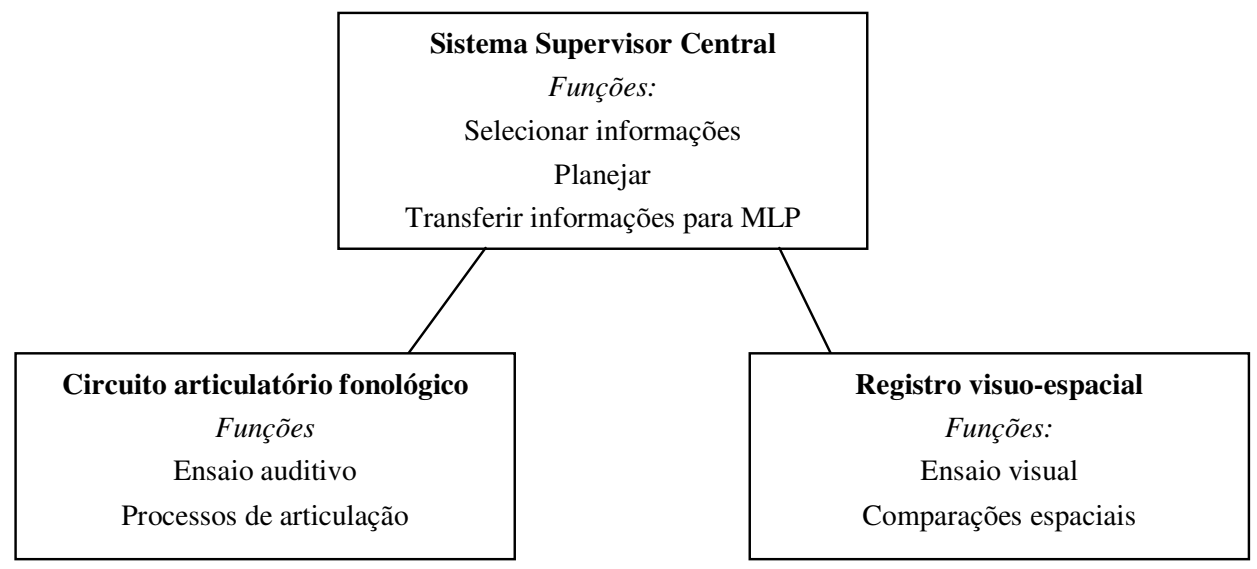

Presume-se que cada um dos três subsistemas tem a sua tarefa e sua capacidade de atenção é limitada. Isto significa dizer que durante o processamento de informação cada qual desempenha sua função sem sobrecarregar o outro. Ao segurar a informação por segundos, os assistentes liberam o SC para desempenhar outras tarefas.

\section{1 - Relação dos sistemas de memória com leitura}

Qual a importância da estrutura da MT no estudo que se propõe a trabalhar com leitura? A simples resposta é: há várias situações nas quais dependemos e confiamos na MT. Uma delas é o fato de a leitura ser uma atividade que requer que se armazene material novo e que ao mesmo tempo este material fique disponível para integrar com informação já adquirida pelo leitor, seu conhecimento de mundo. Em leitura isto pode significar que se o SC é responsável pela tarefa de significação, então não pode haver sobrecarga, uma vez que a informação permanece na MT por poucos segundos.

Pesquisas em leitura em LE têm demonstrado que essa sobrecarga pode ser causada pela falta de conhecimento de vocabulário da língua alvo por parte do leitor menos proficiente

\footnotetext{
*** FONTE: (BRUNING et al, 2004, p.29). Figura 2-5 Um modelo de memória de Trabalho (Traduzido pela autora)
} 
em LE (CARLO e SYLVESTER, 1996). Ao se preocupar em decodificar as palavras, a informação adquirida desde o início da sentença ou parágrafo vai se perdendo pela capacidade limitada do nosso sistema cognitivo.

NUTTALL (p. 75) destaca que para inferir significado de um contexto precisamos ter pistas suficientes. A inferência lexical não ajudará os leitores se todas as palavras, ou a maioria delas, forem inacessíveis. Se o contexto não oferece pistas suficientes a inferência se torna impossível.

Portanto, se o trabalho do leitor com o vocabulário não é uma tarefa automática, se muitas das palavras não se encontram em contextos significativos que permitam a inferência, a leitura de um texto em LE fica bastante prejudicada.

$\mathrm{O}$ aprendiz que lê na língua materna tem uma vantagem enorme sobre os leitores em uma LE. Ele pode se apoiar na habilidade lingüística para compreender. O leitor de língua estrangeira, se não possui o conhecimento do tópico e ainda enfrenta o obstáculo da palavra desconhecida, se sente incapaz de progredir na leitura.

Se levarmos em conta que o reconhecimento de uma palavra é possível se o contexto for significativo, então um leitor menos proficiente não teria sucesso na compreensão ao se deparar com um texto cujo conteúdo lhe é estranho e cujo contexto não é rico o suficiente para compensar a deficiência do léxico. Ou seja, o conteúdo não ajudaria a chegar ao significado.

Sendo os dados lingüísticos inconsistentes para o leitor, haveria uma falha na compreensão, pois ele não conseguiu ativar conhecimento não-lingüístico que poderia interagir com os dados formais para trazer significado. É necessário, então, que o leitor monitore conscientemente e desautomatize as estratégias cognitivas para compreender o que lê, tornando a leitura mais demorada (KLEIMAN, 2004, p. 62-63).

Isso acontece quando o vocabulário do texto não é de domínio do leitor e o contexto não ajuda, as articulações não são lineares ou explícitas. Como explica SCARAMUCCI (1995, p. 258): “Como o número de palavras desconhecidas é muito grande, essa decodificação mobiliza todos os recursos dos leitores, causando uma sobrecarga em sua capacidade de processamento, o que os impede de usar os recursos para construção de um sentido para o texto ou para processamentos de nível mais alto.” Ou seja, a atenção do leitor se volta para a palavra e há uma canalização de esforços, comprometendo a leitura fluente. 
Leitores fluentes conseguem reconhecer as palavras visualmente como uma "fileira de letras conhecida". Experiências repetidas com uma palavra levariam ao desenvolvimento do processo de reconhecimento visual específico daquela palavra. Ao se deparar com ela, seria feito o processamento e o reconhecimento junto com a ativação das informações armazenadas sobre o significado da palavra (HAMPSON e MORRIS, 1996, p. 203).

A partir desta prática, o uso das habilidades mais altas na hierarquia das habilidades de leitura - conhecimento prévio do tópico para inferência, leitura crítica, estratégias de monitoramento da compreensão - que exigem mais atenção, permitiriam que o acesso à informação armazenada na memória semântica fosse mais rápido. Neste nível de leitura, o leitor não precisaria se deter conscientemente no reconhecimento da letra, do som, para chegar ao significado da palavra. Todo este processo ocorreria fora do seu consciente. Quanto maior a velocidade em acessar o significado da palavra, mais eficaz o leitor será em fazer inferências através das sentenças, parágrafos e chegar a uma interpretação que o leve a analisar criticamente o texto. Segundo Perfetti $(1985,1988,2001)$, a capacidade limitada da memória de trabalho dificulta a leitura quando vários processos que exigem atenção precisam ser ativados simultaneamente. Ao se deparar com um texto em língua estrangeira, o leitor menos proficiente irá primeiro travar uma luta inicial com os elementos mais baixos na hierarquia, que são o conhecimento das regras ortográficas de uma língua e o conhecimento lexical, para depois passar para os elementos mais altos, que são o conhecimento sintático e o semântico.

Embora seja uma estratégia útil nas fases iniciais do desenvolvimento da leitura, a exploração do contexto, na verdade, é apenas um estágio e não deve ser o único apoio para compensar a dificuldade vocabular.

\section{3 - As dificuldades do leitor: uma observação sob a luz da teoria VET (Verbal Efficiency}

\section{Theory)}

O estudo apresentado partiu da teoria de Charles Perfetti $(1985,1988,2001)$. A teoria de Perfetti deriva da teoria de processamento de informação. Ela incorpora a noção de que o sistema cognitivo opera sob condições de capacidade limitada:

A memória de trabalho é um sistema de processamento de capacidade limitada cujo obstáculo é o número de elementos da memória que podem ser ativados simultaneamente. Esses elementos não só incluem os nódulos da memória permanente, como as palavras, mas também as ligações 
construídas temporariamente entre os nódulos. Isto é, a memória de trabalho é usada para a compreensão de sentenças. Ela armazena o resultado de sentenças parcialmente processadas, por exemplo, a primeira frase ou oração, e agrupa palavras em sentenças provisórias à medida que são encontradas. (p.100, tradução da autora)

Ou seja, nossa memória de trabalho pode ativar na memória somente um número limitado de elementos num dado momento. Os elementos de seu sub-sistema que se ocuparem com a decodificação de palavras estarão concorrendo com os elementos que se ocupam da interpretação e inferência. Segundo Perfetti, um leitor menos proficiente deve ser levado primeiro a treinar os processos mais baixos na hierarquia das habilidades de leitura a fim de torná-los automáticos: o progresso de decodificação de letras, de palavras e o acesso ao léxico levariam ao progresso na compreensão. Ao ser exposto repetidamente às habilidades mais baixas, o leitor poderia chegar à automatização dos processos cognitivos chegando a um nível que exigiria menos atenção. Outros processos, aqueles mais altos na hierarquia das habilidades de leitura requerem atenção. Isto inclui a aplicação de conhecimento prévio na geração de inferências de nível mais elevado, habilidade de leitura crítica, estratégias de monitoramento da compreensão e outros. $\mathrm{O}$ autor argumenta que um processo de reconhecimento de palavras eficiente ativaria o significado de palavras na memória semântica às custas de mínima atenção.

Perfetti aponta que um leitor mais habilidoso tem um processo de acesso lexical altamente eficiente. Além disso, o texto e o conhecimento do leitor interagem para que a ativação das estruturas de nível mais alto aconteça. A ativação das estruturas acontece principalmente devido às propriedades do texto, mas o leitor deve possuir as estruturas também para que a ativação aconteça. Idealmente, os processos lexicais e esquemáticos acontecem com pouco uso de recursos. Dessa forma, os recursos são alocados para outras tarefas que necessitam de mais atenção: 1) a codificação de proposições, a integração delas dentro e através das sentenças; 2) alguns processos de inferência que não são automáticos, por exemplo, quando o texto apresenta lacunas; 3) a compreensão interpretativa, inferencial e crítica de um texto que vai além do texto escrito.

A VET se solidifica com o argumento de que o acesso lexical é o aspecto crítico na compreensão da leitura. Um acesso rápido e eficiente, que não necessite dos recursos da memória irá permitir que a memória de trabalho conduza o trabalho da integração de proposições e inferência com menos esforço. Portanto, Perfetti propõe a hipótese do acesso lexical em duas formas: primeiro, o acesso lexical tem interferência e, segundo, um acesso lexical ineficiente produz códigos de baixa qualidade. Em relação à interferência, já vimos 
que o acesso lexical e a integração das proposições, cada um na sua proporção, são processos que competem pela atenção do sistema de memória. Como exemplo, Perfetti cita o seguinte trecho:

The room was warm and stuffy so they opened the window.

Ao encontrar opened, o leitor está segurando as proposições sobre a sala estar quente e abafada, que deverá ser ligada à oração iniciada por so. O leitor também já iniciou a montagem das proposições so e they. Com todo esse trabalho acontecendo na memória de trabalho, a palavra opened é acessada. Um acesso a opened rápido e sem esforço produz os códigos semânticos e fonéticos necessários para duas proposições e a palavra window rapidamente completa todas as proposições parcialmente montadas até então. Se o leitor tiver problemas com opened, se ele tiver que dispender sua atenção para acessar o significado da palavra, correrá o risco de perder as proposições parcialmente montadas até então.

A partir da teoria VET, o presente estudo investigou 10 leitores com nível intermediário de fluência em língua inglesa. Esses participantes foram escolhidos por estarem cursando ou por terem concluído a universidade e por utilizarem textos em língua inglesa para aperfeiçoamento acadêmico ou profissional.. A investigação utilizou a metodologia dos protocolos verbais e se baseou nas leituras dos dez sujeitos que, após gravadas, foram transcritas e analisadas para se verificar o quanto da teoria era observável. O texto usado nos protocolos, Cloned animals meet early deaths, é um artigo de divulgação de uma pesquisa científica sobre clonagens. O artigo reascende a discussão sobre a longevidade dos animais clonados. O conhecimento prévio que o leitor deveria possuir era um conhecimento básico de biologia e do tópico específico dentro do domínio da biologia, a clonagem. Há também o conhecimento de cunho científico e de como os cientistas chegam a determinado conhecimento. Esperava-se que os leitores selecionados, pelo seu perfil acadêmico (universitários, pós-graduandos e graduados) possuíssem um conhecimento mínimo do universo científico, de como esse conhecimento é produzido. Esperava-se que os leitores em questão fizessem uma leitura crítica, em que percebessem o debate evidente na exposição dos vários pontos de vista. Além disso, que estabelecessem relações intra-textuais (relações entre as informações já mencionadas no texto) e intertextuais (relação entre a informação trazida pelo texto e outros textos ou notícias divulgados na mídia), de modo a demonstrar uma leitura mais abrangente. 


\section{Conclusão}

Pode-se concluir que a habilidade em superar a deficiência vocabular em um texto em LE varia de leitor para leitor. Embora os participantes tenham sido selecionados a partir de, pelo menos, 400 horas de contato com a língua inglesa, a proficiência na leitura variou muito entre os dez sujeitos. Havia os que conseguiram lidar tranqüilamente com as lacunas e prosseguir a leitura sem ruptura no sentido e outros que se mostraram mais dependentes do processamento local, ou seja, necessitaram extrair sentido de todas as palavras para prosseguir. Porém, a partir do que foi observado neste trabalho, não se pode afirmar que o desempenho na leitura foi o mesmo para o leitor que ignorou o termo que desconhecia e para aquele que ficou reticente. As evidências mostram que dependendo da palavra, da sua função sintática na oração, ignorá-la simplesmente não define um leitor proficiente.

Os dados coletados permitem uma interpretação, dentre várias outras possíveis, de que um leitor que "pula" palavras que não conhece fará uma leitura superficial, impedindo-o, muitas vezes, de perceber os diversos diálogos que um texto trava com outros textos.

A compreensão detalhada, porém, é dificultada não somente pela dificuldade com o léxico da língua em questão. Evidências apontam que o leitor, nesse nível de necessidade de leitura em que se encontra, sendo acadêmico, graduado ou pós-graduando/graduado, precisa possuir o esquema formal de organização desse tipo de texto, que é um artigo de divulgação científica. Essa ausência de conhecimento do esquema formal já pode ser notado no relato do primeiro parágrafo. $\mathrm{O}$ artigo fala do primeiro estudo direto da duração de vida dos camundongos clonados.

Cloned animals may indeed die young suggests the first direct study of their lifespan, carried out by Japanese researchers on mice.

A palavra direto não foi mencionada por sete dos dez sujeitos. Ninguém a sublinhou, o que sugere que a conheciam. No entanto, como era esperado, o leitor poderia não sublinhar um termo achando que o conhecesse, mas o relato poderia revelar o contrário. Porém, a palavra direct é um cognato. Há duas possibilidades para explicar o que pode ter feito sete sujeitos ignorarem-na no relato: a primeira é que, sendo um adjetivo, os leitores não sentiram necessidade de preencher a lacuna, satisfazendo-se com a idéia geral de estudo. Percebe-se, nessa situação, que o processamento ascendente não poderia ter falhado porque direct é um cognato. O que parece ter falhado é o processamento descendente. Então, a segunda possibilidade é que, não possuindo o esquema relativo à pesquisa e ao relato dela, o leitor não 
percebeu o significado de primeiro estudo direto e não se sentindo seguro decidiu ignorar o termo.

A descrição do processo de clonagem feita no segundo parágrafo, embora tenha sido feita com simplicidade, uma abordagem não técnica, não foi compreendida por sete sujeitos:

Cloning involves removing the nucleus from an egg and replacing it with the nucleus of a donor cell. Many of these "nuclear transfer" embryos never develop or miscarry. Even after birth some clones die. But many cloning scientists argue that the few survivors can be perfectly normal.

As evidências levam a acreditar que a principal dúvida foi gerada por uma palavra que não foi sublinhada por nove sujeitos: replacing. Embora haja outras palavras sublinhadas (egg, donor, miscarry) somente três sujeitos conseguiram descrever o processo como uma substituição de um núcleo por outro de uma célula doadora. O termo donor também pode ter causado a má interpretação do processo. É provável que as palavras marcadas e a não marcada replacing tenham impedido que o leitor alocasse os seus recursos de atenção para o processamento de termos não (re)conhecidos e não conseguisse construir um sentido satisfatório. A teoria VET de Perfetti ajuda a explicar a dificuldade: a atenção desviada para o processamento local não permitiu que se percebesse a incoerência nos relatos: por exemplo, célula doadora é a hospedeira (relatado por seis sujeitos). É claro que o termo donor não foi reconhecido por eles, nesse caso, então, replacing poderia ajudar, dando a idéia de substituição, uma vez que a remoção foi compreendida.

O que se pode concluir a partir do relato desse trecho é que, mesmo se o leitor possui o esquema relativo ao tópico que lê, mas encontra obstáculo no vocabulário, sua leitura pode ser prejudicada. O esquema não fôra ativado, portanto, o leitor não consegue superar essa deficiência com conhecimento prévio.

Algumas expressões desconhecidas que se encontram ao final da oração ou do parágrafo não parecem contribuir para uma obstrução na fluência. A sua posição permite que o leitor arrisque mais, já que possui uma quantidade de informação suficiente para tirar uma conclusão. Foi o caso de wishful thinking no parágrafo seguinte:

Rudolf Jaenisch, a mouse cloner at Massachusetts Institute of Technology in Boston says the new work 'shows that to look at animals at one point in time and say they are healthy and normal is really wishful thinking.

Os participantes não interromperam seu relato por não conhecerem a expressão, porém o conjunto de dados permite concluir que o "chute" dá margem a distorções. No caso específico, os leitores tinham dicas, como a segmentação de wish-ful para compensar o 
desconhecimento do termo, mas pode ter sido essa segmentação de uma das palavras da expressão que induziu à má interpretação como, por exemplo, wishful thinking como algo positivo, baseando-se, provavelmente, em wish. Sete sujeitos não perceberam a posição crítica de um pesquisador sobre o tópico representada nessa expressão.

É possível concluir que a palavra é um dos elementos responsáveis pela ruptura na construção de sentido. O contexto em que está inserida, sua função sintática, sua relação com outras idéias ou informações no texto contribuem para atribuir a ela o papel de detonadora da pausa ou ruptura no processamento da leitura. É necessário salientar que a leitura é um processo dinâmico. A mente do leitor parece processar muita informação à medida que tenta tirar sentido do texto: faz relações com conhecimento prévio, com conhecimento recém adquirido, faz seleção do que é coerente e incoerente, estabelece relações intra e intertextuais, busca sentido para palavras isoladas e o adequa à situação, checa pronúncia e a relaciona com algum código semântico, entre outros fenômenos não observáveis. Tudo isso acontece em frações de segundos e tudo isso pode não acontecer porque sua mente está muito ocupada com apenas uma tarefa: encaixar uma palavra ou expressão e se satisfazer com essa adequação de modo a produzir sentido e relatar.

Há uma relação estreita entre o conhecimento do léxico e a ativação do esquema, mas há alguma falha nessa relação e saber como esses elementos funcionam no processamento da leitura é bastante complexo. Não se pode conceber a leitura como um processo linear, estanque e não é possível saber a priori qual elemento vai romper o equilíbrio.

O presente estudo, por ter sido desenvolvido em um ambiente artificial, pode não ser passível de generalização para outras situações, outros públicos e, nem mesmo, para um público semelhante. Não se pode afirmar, tampouco, que os resultados observados possam ser generalizados para outros tipos de textos. Na pesquisa qualitativa assume-se que todo o conhecimento é relativo, que há um elemento subjetivo para cada conhecimento gerado.

Devido à abrangência do complexo processo de leitura, grande parte dos dados coletados não foram analisados devido às limitações do estudo em questão. Acredita-se que o presente estudo possa servir como fonte de pesquisa para futuros pesquisadores que queiram explorar outros aspectos não abordados na sua totalidade.

Os resultados, e todo o processo de pesquisa e observação, contribuíram para que se pudesse acompanhar mais detalhadamente a tarefa da leitura acontecendo. A interação leitor x texto, leitor x pesquisadora ajudou a analisar o complexo processo que é a leitura. Há muito mais acontecendo entre a tarefa de decodificar e a de extrair sentido da palavra impressa. Os 
protocolos contribuíram para que se pudesse ver a luta que o leitor trava nos dois níveis de processamento para poder construir sentido.

Saber a língua só não basta. O leitor precisa ser capaz de utilizar outros recursos como inferência, saber estabelecer relações intra e intertextuais e usar conhecimento de mundo para relacioná-lo com as informações do texto.

Espero que os resultados possam contribuir para o refinamento do instrumento, agregando conhecimento à pesquisa na área de leitura e forneçam inspiração para o trabalho do professor ao abordar o ensino do vocabulário. Por outro lado, acredito que o estudo também tenha contribuído para a percepção de que, muitas vezes, dá-se ao vocabulário um valor tão relevante sem se atentar para outras variáveis que podem estar interferindo na compreensão da leitura. Uma dessas variáveis é o fato de que a organização formal de um texto e os outros esquemas podem não fazer parte do repertório do leitor. Os resultados sugerem que esses fatores interferem na construção de sentido porque a palavra traduzida ou identificada não age sozinha, mas interage com outras idéias do texto ou com informações que estão implícitas.

O objetivo pedagógico ou educacional foi ter contribuído imensamente para a própria prática como docente em cursos de leitura e poder fornecer um parâmetro para outros profissionais. Acredita-se que alguns caminhos foram delineados a partir destes resultados que irão definir a prática de muitos docentes.

\section{Referências}

ADAMS, M. J.; Failures to comprehend and levels of processing in reading. In: R.J. SPIRO, B.C. BRUCE, W.F. BREWER, (Eds.) Theoretical issues in reading comprehension. New Jersey, Lawrence Erlbaum Associates, 1980. p. 11-32. Disponível em: www.questia.com

BRUNING, R. H.; SCHRAW, G. J.; MONICA M. N.; RONNING, R. R. Cognitive psychology and instruction. 4. Ed. New Jersey, USA: Pearson Prentice Hall, 2004.

CARLO, M. S.; SYLVESTER, E. S. Adult second-language reading research: how may it inform assessment and instruction? Pennsylvania: NCAL Technical Report TR96-08. National Center on Adult Literacy, University of Pennsylvania 1996.

CARREL, P. L. Interactive text processing: implications for ESL/second language reading classrooms. In: P. L. CARREL, J. DEVINE, D. E. ESKEY, (Eds.) Interactive approaches to second language reading. New York: Cambridge, 1988. p. 01-36.

HAMPSON, P. J.; MORRIS, P. E. Understanding cognition. Cambridge: Blackwell Publishers, 1996.

KATO, M.A. O aprendizado da leitura. 5a ed., São Paulo: Editora Martins Fontes, 1999. 
MILLER, G. A. The magical number seven, plus or minus two: some limits on our capacity for processing information. Ed. The psychological review, vol. 63, pp. 81-97, 1956.

NUTTALL, C. Teaching reading skills in a foreign language. Oxford: Heinemann English Language Teaching, 1996.

PERFETTI, C.A. Reading ability. New York: Oxford University Press, 1985.

Verbal efficiency in reading ability. In: Reading research: advances in theory and practice, Vol. 6, p. 109-143, 1998.

; HART, L. The lexical basis of comprehension skill. In: D.S. GORFIEN (Ed.). On the consequences of meaning selection: Perspectives on resolving lexical ambiguity. Washington, DC: American Psychological Association, p. 67-86, 2001. Disponível em: http://pitt.edu/ perfetti/charles-perfetti.htm [acesso em setembro de 2005]

PROCAILO, L. Leitura em língua estrangeira: o papel do vocabulário no processamento da informação, f. 183. Dissertação de mestrado inédita, (pós-graduação em lingüística) Universidade Federal do Paraná, Curitiba, 2007.

REISBERG, D. Cognition: Exploring the science of the mind. 2 Ed. New York: W.W. Norton \& Company, 2001.

RICHELS, D. J.; Schema theory, linguistic theory, and representations of reading comprehension. In: W.K. ESTES (Ed.) Handbook of learning and cognitive processes. Hillsdale, N.J: Lawrence Erlbaum Associates, 1978. Disponível em: www.questia.com

ROTT, S. Processing glosses: A qualitative exploration of how form-meaning connections are established and strengthened. Reading in a Foreign Language, vol. 17, No. 2, p. 95-124, out. 2005. Disponível em http://n[]re.hawaii.edu/r[] [acesso em Janeiro de 2006]

RUMELHART, D.E.; Schemata: the building blocks of cognition. In: R.J. SPIRO, B.C. BRUCE, W.F. BREWER, (Eds.) Theoretical issues in reading comprehension. New Jersey, Lawrence Erlbaum Associates, 1980. p. 33-59. Disponível em: www.questia.com

SAMUELS, S. J.; KAMIL, M. L. Models of the Reading Process. In: R. BAN, M. KAMIL, P. MOSENTHAL, (Eds) Handbook of reading research. Vol. I. New Jersey: Lawrence Erlbaum Associates, 2002. p. 185-224. Disponível em: www.questia.com

SCARAMUCCI, M. V. R. O papel do léxico na compreensão em leitura em língua estrangeira: foco no produto e no processo. Campinas, 1995. Tese (Doutorado em Ciências) - Instituto de Estudos da Linguagem, Universidade Estadual de Campinas, São Paulo.

STERNBERG, R.J. Psicologia cognitiva. Trad. Maria Regina Borges Osório. Porto Alegre: Artes Médicas Sul, 2000.

SCHANK, R.C.; ABELSON, R.P. Scripts, plans, goals and understanding: an inquiry into human knowledge structures. Hillsdale, N.J: Lawrence Erlbaum Associates, 1977. Disponível em: www.questia.com 


\title{
APÊNDICE
}

\author{
Cloned animals meet early deaths \\ 19:00 10 February 2002 \\ From New Scientist Print Edition. \\ Philip Cohen
}

Cloned animals may indeed die young suggests the first direct study of their lifespan, carried out by Japanese researchers on mice.

Cloning involves removing the nucleus from an egg and replacing it with the nucleus of a donor cell. Many of these "nuclear transfer" embryos never develop or miscarry. Even after birth some clones die. But many cloning scientists argue that the few survivors can be perfectly normal.

Atsuo Ogura of the National Institute of Infectious Diseases in Tokyo says his team's work suggests that some effects of cloning are not apparent in the days, weeks or even years after birth. "It is very probable that, at least for some populations of clones, some unpredictable defects will appear in the long run," he says.

The debate over the health of clones and how they age has swung one way and then the other. In November 2001, US biotech company Advanced Cell Technology reported the cloning of two dozen apparently healthy cloned cows. But in January, the first mammal cloned from an adult cell, Dolly the sheep, was reported to have prematurely developed arthritis.

Rudolf Jaenisch, a mouse cloner at Massachusetts Institute of Technology in Boston says the new work "shows that to look at animals at one point in time and say they are healthy and normal is really wishful thinking."

\section{Immune system defect}

Ogura's team cloned 12 male mice and these were compared with seven males from natural matings and six others produced using in vitro fertilisation. The clones appeared active and healthy, gained weight normally and matched the control animals in 14 of 16 physiological measurements.

But the first cloned animal died after only 311 days and, by day 800, 10 (83 per cent) of the animals were dead. In contrast, only three ( 23 per cent) of the controls died during the same period.

The dead clones showed high rates of pneumonia, liver disease, cancer and a lower level of antibody production, suggesting they had an immune system defect. Ogura's team is now trying to pinpoint the precise cause of death and repeat the experiment with more animals.

ACT's Tony Perry points out that it remains unclear if clones from other species such as cows or pigs die early. And even if clones in general do prove to have a shortened lifespan, he does not think that undermines data from ACT and others that clones can be healthy.

All the researchers agree that the work should be an additional warning to would-be human cloners.

Journal reference: Nature Genetics (DOI: 10.1038/ng841)

http://www.newscientist.com/article/dn1903.html. Acessado em 26 de março de 2006, 12:10 